\title{
Airway management in retrosternal goitre with tracheal compression: an alternative approach
}

\author{
S Prasad ${ }^{1 *}, Y$ Gaude ${ }^{2}$, M Prabhu ${ }^{3}$ \\ Junior Consultant ${ }^{1 *}$, Lourdes Hospital, Kochi, Kerala, India, Assistant Professor ${ }^{2}$, Professor ${ }^{3}$, \\ Kasturba Medical College, Manipal University, Karnataka, India.
}

Editor,

The "best" method for managing a difficult airway is a subjective matter. This implies that there are several "best" methods for each case and it ultimately boils down to the concerned anaesthetist to choose one. Here we would like to suggest our "best" method of airway management in a patient with retrosternal goitre and documented tracheal compression. A 55-year-old diabetic female presented with a swelling on the anterior aspect of neck for one month associated with sore throat. No history of compressive symptoms. She underwent a thyroid surgery 20 years back for a similar swelling. Preoperative examination revealed a thyroid swelling with retrosternal extension. Kocher's and Pemberton's tests were negative. A computed tomography scan of neck and chest revealed enlarged thyroid extending to superior mediastinum up to the arch of aorta with $>50 \%$ compression and distortion of the tracheal lumen. (Figure 1)

Video directed stroboscopy showed bilateral mobile vocal cords. Being an anticipated difficult airway, written informed consent was obtained for possible on table tracheostomy, postoperative intensive care unit admission and mechanical ventilation. Just like any case of difficult airway, we had several options in mind and opinions were taken from senior anaesthetists in the department.

After the brain storming session, we decided on the following plans.

\footnotetext{
*Correspondence: S Prasad

E mail: sethu2401@gmail.com

https://orcid.org/0000-0003-0884-9239

Received: $20 / 11 / 2017$

Accepted: 04/12/2017

DOI: http://doi.org/10.4038/slja.v26i1.8293
}

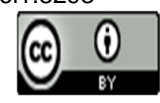

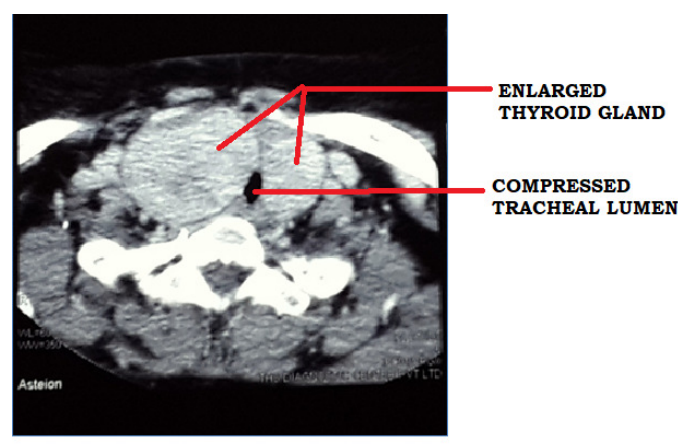

Figure 1: CT scan showing enlarged thyroid gland and compressed trachea

Plan A was intravenous induction, depolarizing neuromuscular blockade, quick fibreoptic bronchoscopy and FOB guided intubation. Plan B was to bring the patient back to spontaneous breathing, perform an awake or sedated FOB guided intubation and plan $\mathrm{C}$ was rigid bronchoscopy and jet ventilation. Plan D included a high tracheostomy or cardiopulmonary bypass. Prior to induction, difficult airway cart and above-mentioned equipment was kept ready in the operation theatre. Also, an ENT and cardiothoracic surgeon were informed to be standby in case of inability to maintain airway. Since she was clinically asymptomatic, we proceeded with Plan A: intravenous induction. Titrated induction was done with fentanyl and propofol, bag and mask ventilation was confirmed and neuromuscular blockade obtained with succinyl choline. Under direct laryngoscopic vision, a $7 \mathrm{~mm}$ ID cuffed endotracheal tube (ETT) was passed till the tip of tube was at the level of vocal cords. This provided the option to immediately pass the tube into trachea in case the patient desaturated during bronchoscopy and also an easy and low resistance conduit for the FOB till the vocal cords. A quick bronchoscopy was done through ETT to rule out intra-tracheal invasion of the growth and ETT was rail-roaded over FOB (Figure 2). 


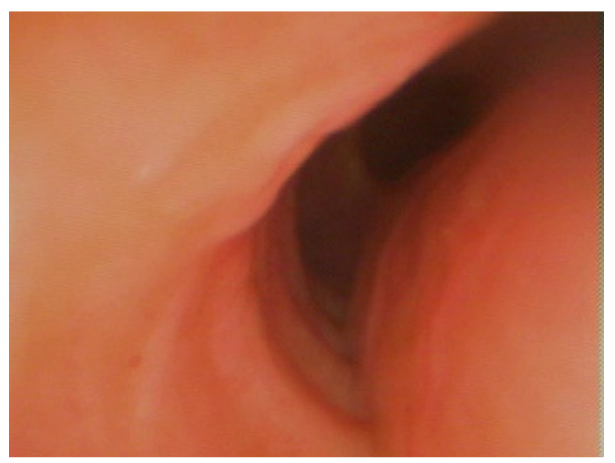

Figure 2: Fibreoptic bronchoscopic image of compressed tracheal wall

After confirmation of ETT position, intravenous vecuronium was given. Intraoperatively, tracheomalacia was noted by the surgeon. An ontable tracheostomy was deferred due to extremely thinned out tracheal wall. At end of surgery, after reversal of neuromuscular blockade, a cuff leak test was performed. Due to absence of leak around cuff, patient was shifted to ICU with ETT insitu. In ICU, patient was maintained on T-piece with spontaneous ventilation. After 5 days, patient was shifted to operation theatre for extubation under FOB guidance.

Retrosternal goitre is theoretically associated with risk of airway problems and post-operative tracheomalacia. ${ }^{1}$ However, intravenous induction and conventional laryngoscopy guided intubation is found safe in experienced hands ${ }^{1}$.

Prolonged duration and retrosternal extension are considered as risk factors for post-thyroidectomy tracheomalacia (PTTM) but recent studies have failed to support this ${ }^{1-3}$. Management includes reintubation, tracheal stenting or tracheostomy based on severity. Careful extubation and postoperative care improves outcomes.

Awake flexible fibre optic bronchoscope guided intubation (AFOI) is universally considered the "best" and recommended method for anticipated difficult airway by experts. This is probably due to its better safety profile. However, this conventionally preferred method becomes risky in patients with severe tracheal compression, due to the possible occlusion of the only available tracheal lumen by FOB leaving no space for the patient to breathe. The consequences are desaturation, restlessness and an unsuccessful AFOI. Hence, this alternative method helps intubating such patients without significantly compromising the ability to ventilate. This case supports the observation by Cook et al. that when it comes to difficult airway management, even experts never agree to each other ${ }^{4}$. However, this method does pose the risk of losing the airway which highlights the need for backup plans. Since the "best" can never be chosen without trying out the "better" options, maybe it is time to try out other methods of airway management as well.

\section{References}

1. Dempsey GA, Snell JA, Coathup R, Jones TM. Anaesthesia for massive retrosternal thyroidectomy in a tertiary referral centre. $\mathrm{Br} \mathrm{J}$ Anaesth 2013; 111(4); 594-9.

https://doi.org/10.1093/bja/aet151 PMid:23690528

2. Findlay JM, Sadler GP, Bridge H, Mihai R. Postthyroidectomy tracheomalacia: minimal risk despite significant tracheal compression. $\mathrm{Br} \mathrm{J}$ Anaesth 2011; 106: 903-6.

https://doi.org/10.1093/bja/aer062 PMid:21450708

3. Huins CT, Georgalas C, Mehrzad H, Tolley NS. A new classification system for retrosternal goiter based on a syatematic review of its complications and management. Int J Surg 2008; 6: 71-6. https://doi.org/10.1016/j.ijsu.2007.02.003 PMid:17416216

4. Cook TM, Morgan PJ, Hersch PE. Equal and opposite expert opinion. Airway obstruction caused by a retrosternal thyroid mass: management and prospective international expert opinion. Anaesthesia 2011; 66: 828-36. https://doi.org/10.1111/j.13652044.2011.06650.x PMid:21486272 